Original Research Paper

\title{
Antibacterial and Anti-Quorum Sensing Activities of Selected Italian Honeys against Antibiotic-Resistant Pathogens
}

\author{
Marco Fidaleo, Roberto Lavecchia and Antonio Zuorro \\ Department of Chemical Engineering, Materials and Environment, Sapienza University, Rome, Italy
}

Article history

Received: $20-05-2015$

Revised: 20-08-2015

Accepted: 22-10-2015

Corresponding Author: Roberto Lavecchia Department of Chemical Engineering, Materials and Environment, Sapienza University, Rome, Italy Email: roberto.lavecchia@uniroma1.it

\begin{abstract}
Three nectar honeys (eucalyptus, thyme and forest) and two honeydew honeys (fir and Metcalfa) from Italy were tested for their antibacterial activity against pathogens commonly associated with wound and burn infections, including Methicillin-Resistant Staphylococcus Aureus (MRSA), methicillin-resistant Staphylococcus epidermidis (MRSE) and Vancomycin-Resistant Enterococcus Faecalis (VREF). All honeys showed bactericidal activity against the microorganisms used, with honeydew honeys being the most effective. They also inhibited, in a dosedependent manner, violacein production in Chromobacterium violaceum, thus demonstrating their ability to affect quorum sensing-regulated biofilm formation. Overall, the results obtained suggest that the honeys examined may have potential for developing natural antimicrobial compositions or dressings for the treatment of infected wounds or burns.
\end{abstract}

Keywords: Honey, Antibacterial Activity, Quorum Sensing, Antibiotic Resistance, Wound Pathogens

\section{Introduction}

Resistance to antibiotics continues to rise worldwide, but the rate of discovery of new antibiotics has steadily decreased over the last 20 years (Livermore, 2011). The reasons behind the lack of antibiotic discoveries are diverse and include, among others, the poor return on investment, compared to drugs for chronic diseases, and regulatory burdens for smaller pharmaceutical companies (Silver, 2011).

Infections caused by resistant pathogens can often be treated using antibiotic cocktails, that is, a combination of existing antibiotics with different mode of actions. However, the emergence of multi-resistant bacterial strains (Rossolini et al., 2014) and the formation of bacterial biofilms that are difficult, if not impossible, to eradicate (Wu et al., 2015) have prompted efforts to find alternatives to current antibiotic therapy.

Honey is an ancient natural remedy for the treatment of infected wounds. With the advent of antibiotics, therapeutic applications of honey were largely abandoned, but recent studies on its antibacterial and wound healing properties have stimulated a renewed interest in its use (Vandamme et al., 2013). The results of these studies indicate that some types of honey have high in vitro activity against both Gram-positive and Gram-negative bacteria and support their use in the treatment of infections not responding to antibiotics (Kwakman et al., 2011).
Another point of interest is that resistance to honey has never been reported to date, or any toxicity or side effects associated with its use have been found (Mandal and Mandal, 2011). Furthermore, honey seems to have more than just bactericidal activity, as it can affect Quorum Sensing (QS), i.e., the mechanism by which bacteria control gene expression in response to cell density (Maddocks and Jenkins, 2013). QS is implicated in a number of pathologically relevant events such as biofilm formation, drug resistance and virulence factor production.

A study conducted by Truchado et al. (2009a) on 29 unifloral honeys showed that most of them were capable of interfering with QS. Chestnut and linden honeys had the highest anti-QS activity, whereas orange and rosemary honeys were less effective. Later studies conducted on New Zealand manuka (Leptospermum scoparium) honey revealed that this type of honey can inhibit biofilm formation of clinically important pathogenic bacteria such as Staphylococcus aureus (Lu et al., 2014), Proteus mirabilis (Majtan et al., 2014) and Clostridium difficile (Hammond et al., 2014).

Although the aforementioned studies provide encouraging evidence for the efficacy of honey in treating wound infections, there is a need to further explore this issue, particularly in relation to the anti-QS and anti-biofilm properties of honey.

In this study we investigated the antibacterial potential of some Italian honeys against bacteria 
commonly associated with infected wounds. The bacterial strains examined included Methicillin-Resistant Staphylococcus Aureus (MRSA), Methicillin-Resistant Staphylococcus Epidermidis (MRSE) and VancomycinResistant Enterococcus Faecalis (VREF), three pathogens that are currently of great concern because of their implication in life-threatening nosocomial and community-acquired infections.

\section{Materials and Methods}

\section{Chemicals}

Chloramphenicol (CAS 56-75-7), methicillin sodium salt (CAS 132-92-3), vancomycin (CAS 1404-90-6), oxacillin (CAS 66-79-5), dimethyl sulfoxide (DMSO, CAS 67-68-5), Mueller-Hinton Agar 2 (MH2) and Mueller-Hinton (MH) broth were purchased from Sigma-Aldrich (Milano, Italy). Nutrient Broth 6067 (NB) was obtained from KairoSafe (Duino Aurisina, Italy). All other chemicals were analytical grade and used without further purification.

\section{Bacterial Strains}

Staphylococcus aureus (ATCC 43300), Staphylococcus epidermidis (ATCC 29887), Enterococcus faecalis (ATCC 51299), Burkholderia cepacia (ATCC 25416), Pseudomonas aeruginosa (ATCC 10145) and Chromobacterium violaceum (LMG 1267) were purchased from KairoSafe (Duino Aurisina, Italy).

Methicillin-resistant Staphylococcus epidermidis (MRSE), isolated from an infected surgical wound, was obtained from Tor Vergata University Hospital (Rome, Italy).

\section{Honeys}

Honeys were obtained from Rigoni di Asiago (Asiago, VI, Italy) and consisted of three nectar (eucalyptus, thyme and forest) and two honeydew (fir HD and Metcalfa HD) honeys. They were collected from beehives in different locations in Italy and cold processed at temperatures below $30^{\circ} \mathrm{C}$.

Honey samples were placed in glass containers and stored in the dark at room temperature until use.

\section{Honey Sterilization}

The honey samples tested were sterilized, after dissolution in the appropriate growth medium, by filtration on a $0.22 \mu \mathrm{m}$ Millipore ${ }^{\circledR}$ filter.

\section{Agar-Well Diffusion Assay}

Agar-well diffusion tests were carried out according to NCCLS guidelines as described in a previous paper (Fidaleo et al., 2010). Bacterial cells from an exponential-phase culture grown in $\mathrm{MH}$ broth were spread on the surface of agar (MH2) plates using a sterile swab soaked in the bacterial suspension. $9 \mathrm{~mm}$ wells were then cut in the agar and filled with $150 \mu \mathrm{L}$ of honey. After $18 \mathrm{~h}$ incubation at $37^{\circ} \mathrm{C}$, the plates were examined and the diameters of the inhibition zones measured. Chloramphenicol $(30 \mu \mathrm{g})$, methicillin $(5 \mu \mathrm{g})$ vancomycin $(10 \mu \mathrm{g})$ and oxacillin $(10 \mu \mathrm{g})$ were used as positive controls.

\section{Determination of MIC}

Minimum Inhibitory Concentration (MIC) was determined by the two-fold serial dilution technique. The starting honey solution $(33 \% \mathrm{w} / \mathrm{v})$ was prepared by dissolving each honey in $\mathrm{MH}$ broth. Bacteria from an exponential culture were inoculated at about $1.5 \times 10^{6}$ $\mathrm{CFU} / \mathrm{mL}$ in tubes containing the appropriate honey concentration. Test tubes were incubated at $37^{\circ} \mathrm{C}$ for $16-$ $18 \mathrm{~h}$. Subcultures were then streaked on $\mathrm{MH} 2$ agar plates, which were incubated at $37^{\circ} \mathrm{C}$ for $18 \mathrm{~h}$. Finally, the number of colonies formed on each plate was counted. The MIC value was determined as the lowest honey concentration giving complete inhibition of bacterial growth.

\section{Determination of $M B C$}

Minimum Bactericidal Concentration (MBC) was determined by the two-fold serial dilution technique. The starting honey solution $(33 \% \mathrm{w} / \mathrm{v})$ was prepared by dissolving each honey in $\mathrm{MH}$ broth. Bacteria from an exponential culture were inoculated at about $1.5 \times 10^{6}$ $\mathrm{CFU} / \mathrm{mL}$ in tubes containing the appropriate honey concentration. Tubes were incubated at $37^{\circ} \mathrm{C}$ for $16-18$ h. Subcultures were then streaked on $\mathrm{MH} 2$ agar plates, which were incubated at $37^{\circ} \mathrm{C}$ for $18 \mathrm{~h}$. Finally, the number of colonies formed on each plate was counted. The MBC value was determined as the lowest honey concentration killing $99.9 \%$ of the original inoculum.

\section{Anti-Quorum Sensing Activity Assay}

Anti-quorum sensing activity was determined by evaluating the ability of honey to inhibit the production of violacein in the $C$. violaceum model system as reported by Fidaleo et al. (2013).

C. violaceum was cultured aerobically in $\mathrm{NB}$ at $28{ }^{\circ} \mathrm{C}$ for $16-18 \mathrm{~h}$. Forty $\mu \mathrm{L}$ of the culture were inoculated in tubes containing the appropriate concentration of honey in $\mathrm{MH}$ to achieve a suspension equivalent to 0.5 McFarland standard. Test tubes were incubated at $37^{\circ} \mathrm{C}$ for $18 \mathrm{~h}$, after which time an aliquot of $1 \mathrm{~mL}$ was taken and centrifuged at $16,000 \times \mathrm{g}$ for $10 \mathrm{~min}$ to precipitate the insoluble violacein. The culture supernatant was discarded and $1 \mathrm{~mL}$ of DMSO was added to the pellet. Then, the solution was centrifuged at $16,000 \times \mathrm{g}$ for 10 min and the amount of violacein in the supernatant was determined spectrophotometrically at $585 \mathrm{~nm}$. 


\section{Results}

Preliminary tests on the bacterial strains used showed that $S$. aureus ATCC 43300, S. epidermidis ATCC 29887 (MRSE A) and $S$. epidermidis isolated from the infected wound (MRSE B) were methicillin resistant. $S$. aureus ATCC 43300 was also oxacillin resistant, while E. faecalis ATCC 51299 was vancomycin resistant.

The results obtained by the agar-well diffusion method are presented in Fig. 1. The five honeys were all active, but to varying degrees, against the six pathogens tested. Metcalfa HD honey was the most effective, followed by fir HD, thyme, eucalyptus and forest honeys.
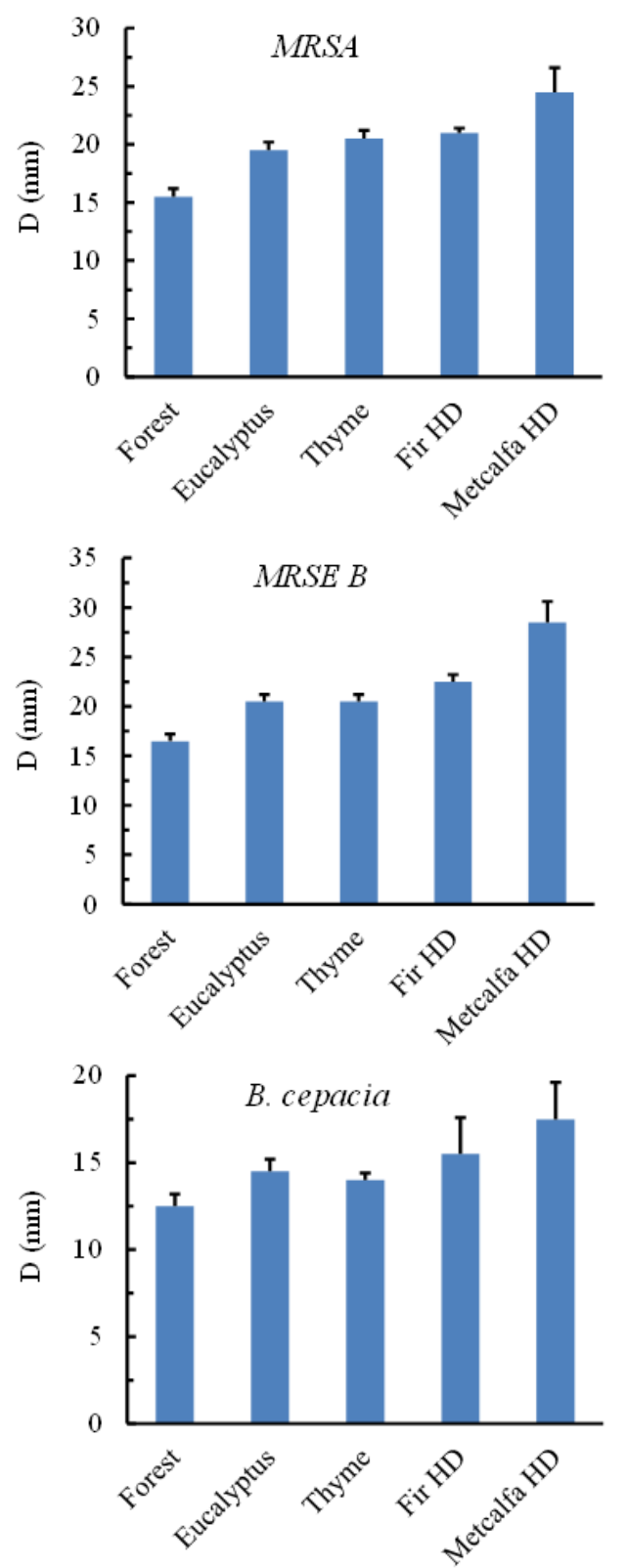

In general, Gram-positive bacteria were more susceptible to honeys than Gram-negatives, with the exception of $E$. faecalis, whose sensitivity was comparable to that of $B$. cepacia and $P$. aeruginosa.

To investigate the intrinsic antibacterial activity of honeys, i.e., to assess whether the observed inhibitory effects were bactericidal or bacteriostatic, the MIC and MBC for each bacterial strain were determined.

The observed MICs and MBCs ranged from 8.33 to $33.3 \%(\mathrm{w} / \mathrm{v})$. Some representative results, referring to MRSA (Gram-positive) and B. cepacia (Gram-negative) are reported in Table 1.
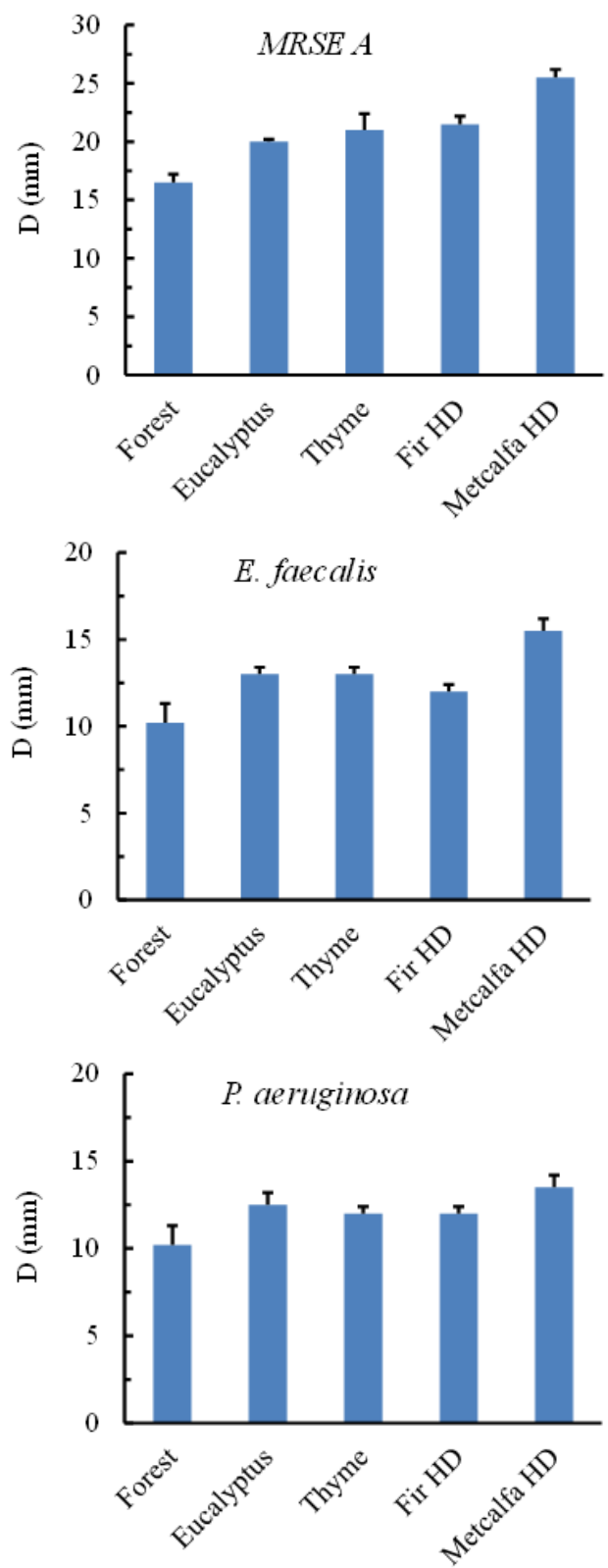

Fig. 1. Antibacterial activity of honeys against the six pathogens tested. D is the diameter of inhibition zone 


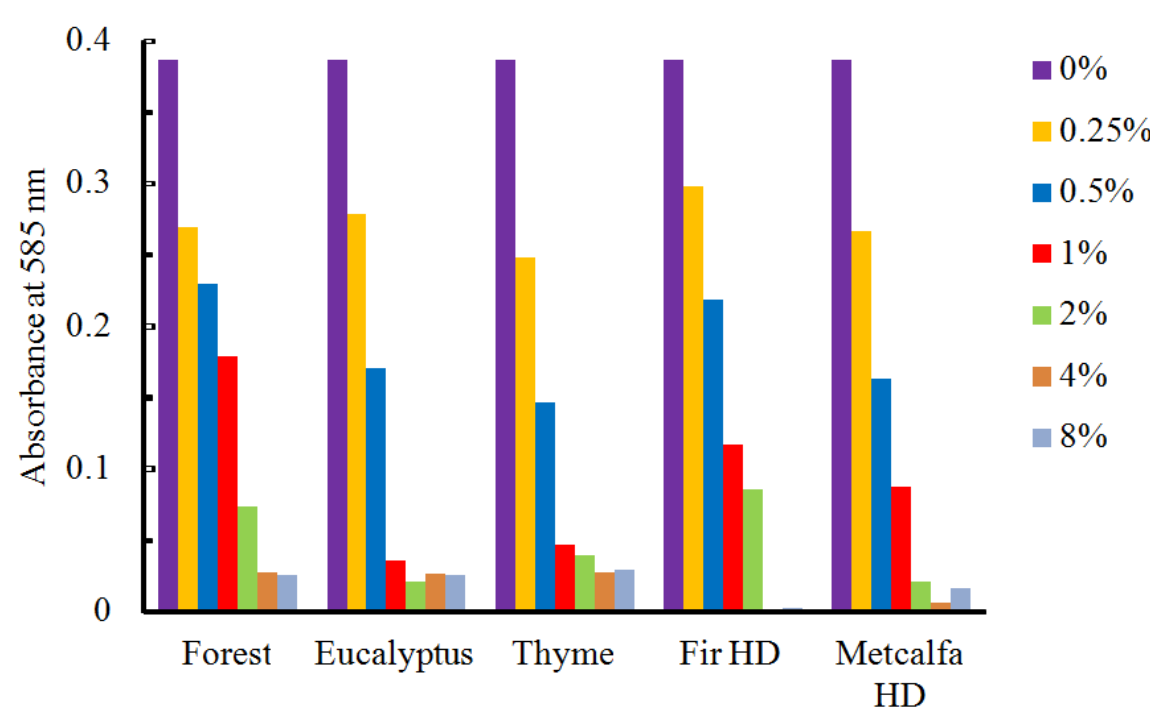

Fig. 2. Effect of honeys at concentrations up to $8 \%(\mathrm{w} / \mathrm{v})$ on violacein production

Antibacterial activity

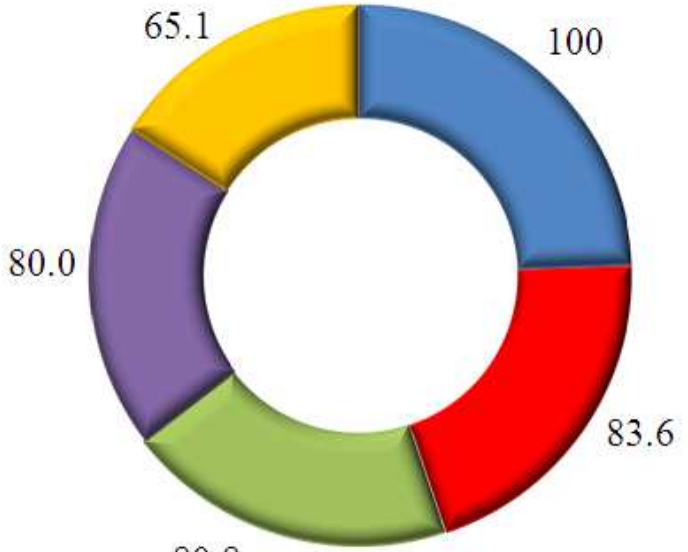

80.8

Anti-QS activity

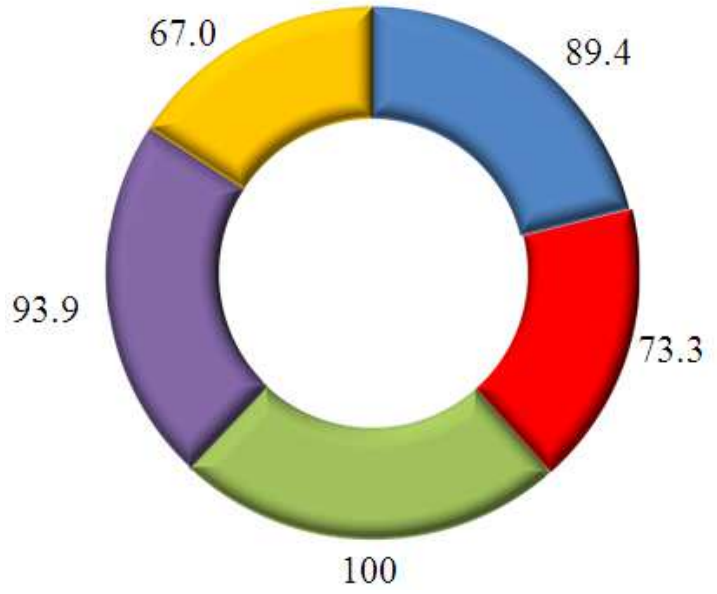

Metcalfa HD

- Fir HD

四 Thyme

Eucalyptus

Forest

Metcalfa HD

air HD

Thyme

Eucalyptus

$\Delta$ Forest

Fig. 3. Average antibacterial and anti-QS activities of the five honeys 
Table 1. Minimum inhibitory concentration (MIC) and minimum bactericidal concentration (MBC) of honeys against MRSA and B. cepacia

\begin{tabular}{lllll}
\hline & MRSA & \multicolumn{3}{c}{ B. cepacia } \\
& - & - & - & - \\
& MIC & MBC & MIC & MBC \\
Honey type & $(\% \mathrm{w} / \mathrm{v})$ & $(\% \mathrm{w} / \mathrm{v})$ & $(\% \mathrm{w} / \mathrm{v})$ & $(\% \mathrm{w} / \mathrm{)}$ \\
\hline Forest & 33.3 & 33.3 & 33.3 & 33.3 \\
Eucalyptus & 8.33 & 16.7 & 16.7 & 16.7 \\
Thyme & 8.33 & 8.33 & 16.7 & 16.7 \\
Fir HD & 8.33 & 16.7 & 16.7 & 33.3 \\
Metcalfa HD & 8.33 & 8.33 & 16.7 & 33.3 \\
\hline
\end{tabular}

Table 2. Minimum inhibitory concentration (MIC) of honeys against $C$. violaceum and percentage change in absorbance at $585 \mathrm{~nm}\left(\Delta \mathrm{A} / \mathrm{A}_{0}\right)$ for honey concentrations ranging from 0.25 to $1 \%(\mathrm{w} / \mathrm{v})$

\begin{tabular}{lllll}
\hline & & \multicolumn{4}{l}{$\Delta \mathrm{A} / \mathrm{A}_{0}(\%)$} \\
Honey type & $(\% \mathrm{w} / \mathrm{v})$ & $0.25 \%$ & $0.5 \%$ & $1 \%$ \\
\hline Forest & 8.33 & 30.2 & 40.6 & 53.7 \\
Eucalyptus & 2.08 & 27.9 & 55.8 & 90.7 \\
Thyme & 2.08 & 35.9 & 62.0 & 87.9 \\
Fir HD & 4.17 & 23.0 & 43.4 & 69.8 \\
Metcalfa HD & 4.17 & 31.0 & 57.9 & 77.3 \\
\hline
\end{tabular}

Figure 2 shows the effect of honeys on violacein production in the $C$. violaceum model system. All honeys significantly reduced the production of violacein in a dose-dependent fashion. Furthermore, the inhibitory activity occurred at sub-MIC levels (Table 2), which demonstrates that the honeys were capable of interfering with the QS signaling system.

From the observed percentage decrease in violacein production at low honey concentrations $(0.25-1 \% \mathrm{w} / \mathrm{v})$ (Table 2$)$, the following order of effectiveness can be established:

Thyme $>$ eucalyptus $>$ metcalfa HD $>$ fir HD $>$ forest

Interestingly, the QS inhibitory activity order did not parallel the antibacterial activity order. This can be easily seen in Fig. 3, where the anti-QS activity of the honeys (calculated from the data in Table 2) is compared with their average anti-bacterial activity against the six pathogens tested. These results clearly suggest that different mechanisms are involved in the two phenomena.

\section{Discussion}

This study was focused on six pathogens ( $P$. aeruginosa, B. cepacia, E. faecalis, MRSA and two strains of MRSE) that are frequently implicated in wound and burn infections. Management of these infections is complicated by the emergence of multiple drug resistance strains and by the fact that bacteria at the wound site are often organized in biofilm structures. Biofilms act as a barrier to the penetration of both immune system components and antimicrobials, making antibiotic treatment difficult and potentially unsuccessful (Hall et al., 2014).

In a previous study on the effect of Italian honeys of different floral origin and geographical location on model bacteria, we found that they exhibited a wide range of antibacterial activity (Fidaleo et al., 2011). Some of them showed no activity at all, while others, like eucalyptus and fir HD honeys, were particularly effective. These two honeys were therefore included, together with thyme, forest and Metcalfa HD honeys, in the present study to assess their antibacterial and anti-QS activities against the selected pathogens.

The first point that emerges from our data is that the honeys tested not only inhibited bacterial growth but also killed the bacteria. Methicillin-resistant Staphylococcus species (MRSA, MRSE A and MRSE B) were the most sensitive to honey. In recent years, MRSA and MRSE have become the most important cause of nosocomial and device-related infections. Their presence in infected wounds can cause delayed wound healing and other complications (Otto, 2009; Purrello et al., 2014). Furthermore, their ability to form biofilms on living or inert surfaces makes infections poorly responsive to antibiotic treatment (O'Gara and Humphreys, 2001).

A second point to note is the higher sensitivity of Gram-positive bacteria to the honeys tested. This is in agreement with previously reported results for Maleysian (Zainol et al., 2013) and other (Cooper et al., 2002; Basualdo et al., 2007) honeys. Moreover, similar results were obtained in studies using essential oils (Andrade et al., 2014) and plant extracts (Klancnik et al., 2010) as antimicrobial agents. The lower susceptibility of Gram-negative bacteria could be due to the presence, in these organisms, of an outer lipopolysaccharide membrane in addition to the inner peptidoglycan layer, hindering the penetration of bioactive components into the cell (Pagès et al., 2008).

The precise mechanisms of action of honey are not fully understood. Evidence so far seems to indicate that different factors may contribute to the antibacterial properties of honey, including high osmolarity, low $\mathrm{pH}$, hydrogen peroxide and the presence of non-peroxide components of flower or bee origin (Kwakman and Zaat, 2012).

The high osmolarity of honey is due to the high content of sugars $(\sim 80 \% \mathrm{wt} / \mathrm{vol})$, which lowers water activity and inhibit bacterial growth. Although this factor may have some influence on bacterial growth in undiluted or low-diluted honeys, it is unlikely that it would be significant in our case, given the observed MICs and MBCs. Regarding hydrogen peroxide, we found that catalase treatment of the honeys did not cause 
appreciable changes in antibacterial activity (data not shown here). Thus, we can hypothesize that the antibacterial properties of the honeys tested are mainly due to the presence of active compounds whose identity remains to be established.

To date, only a few substances, such as methylglyoxal in Manuka honey (Mavric et al., 2008) and the antimicrobial peptide bee defensin-1 in Revamil ${ }^{\circledR}$ honey (Kwakman et al., 2011), have been definitely identified as responsible for the antibacterial activity of those honeys. Other honey components, such as phenolic compounds originating from plant nectar or, in HD honeys, from excretions of plant-sucking insects, have been proposed as possible antibacterial agents. Several phenolics have so far been identified in honeys, including caffeic, p-coumaric and ellagic acids (Escuredo et al., 2012), diglycosyl flavonoids and terpenes (Massaro et al., 2014). While most of them have antibacterial activity, their contribution to the antibacterial properties of honey is still unclear. Because of the low concentrations at which these substances are present in honey, it is believed that their combination, rather than their individual occurrence, is responsible for the observed activity (Kwakman et al., 2011). Consistent with this hypothesis, some types of honey were found to synergistically enhance the activity of antibiotics having different mechanisms of action, suggesting that honey may contain multiple active components affecting more bacterial target sites (Jenkins and Cooper, 2012).

The third and perhaps most important point emerging from the present study is the ability of the five honeys tested to inhibit QS. The possibility of controlling this cell-to-cell communication mechanism is considered crucial for the development of next-generation antimicrobials. This is because QS regulates the production of many virulence factors, including biofilm formation, which plays a key role in antibiotic resistance as well as the pathogenesis of many clinically relevant infections (Hall et al., 2014).

QS involves the synthesis, excretion and detection of small signal molecules known as autoinducers. They consist of oligopeptides in Gram-positive bacteria and Acylated Homoserine Lactones (AHLs) in Gramnegative bacteria. Except for the halogenated furanones from the red alga Delisea pulchra, most of the identified anti-QS compounds are of plant origin (Nazzaro et al., 2013).

Very few studies have been conducted on QS inhibition by honey and no conclusive evidence has yet been obtained on the compounds responsible for it. In a study on acacia and multifloral Korean honeys, Lee et al. (2011) found that low concentrations of these honeys $(0.5 \% \mathrm{v} / \mathrm{v})$ were capable of reducing biofilm formation in an enterohemorrhagic E. coli strain. Glucose and fructose appeared to be the main contributors to biofilm inhibition, although this is not consistent with the fact that honeys having similar glucose and fructose content may behave in a very different way. Truchado et al. (2009b) studied the effect of chestnut honey and its aqueous and methanolic extracts on biofilm formation by Erwinia carotovora, Yersinia enterocolitica and Aeromonas hydrophila. Chestnut honey and the aqueous extract showed a significant QS inhibitory activity, while the methanolic extract did not have any effect. Furthermore, QS inhibition resulted from both the degradation of AHLs and the inhibition of AHL production by the bacterial strains. In another study on the inhibitory properties of selected phenolic compounds on two of the above strains ( $E$. carotovora and $Y$. enterocolitica), it was found that some of them, including rutin, ellagic and chlorogenic acids, were capable of reducing the concentration of ALHs (Truchado et al., 2012). Recently, Savka et al. (2015) showed that pinocembrin, a flavonoid that regulates immune genes in the western honey bee Apis mellifera, can disrupt AHL-dependent QS in bacteria. This suggests that phenolic honey constituents may play a role in QS inhibition, although current evidence does not allow definitive conclusion to be drawn on their contribution.

\section{Conclusion}

The worldwide increase in antibiotic resistance and the shortage of new antibiotics are driving interest in novel antimicrobial agents acting through alternative mechanisms, such as inhibition of QS, which is known to control bacterial adhesion to surfaces, biofilm formation and stimulation of virulence.

The honeys investigated in this study were found to have both bactericidal and anti-QS activities against human pathogens commonly associated with wound and burn infections. In particular, they exhibited high antibacterial activity against MRSA and MRSE, whose prevalence in nosocomial and community-acquired infections is increasing dramatically. These properties support their use to treat infections not responding to antibiotic therapy or to prevent biofilm formation on medical devices. Because of the low cost of honey, compared to antibiotics, the development of honey-based antibacterial products could also have important economic implications for the health care system.

Future studies should provide insight into the mechanisms by which the honeys tested exert their beneficial effects and explore the possibility of blending different types of honey to maximize antibacterial efficacy.

\section{Acknowledgement}

The authors gratefully thank "Rigoni di Asiago SRL" (Asiago, VI, Italy) for the kind gift of honey samples. 


\section{Funding Information}

This work was supported by grants from Sapienza University of Rome (Italy).

\section{Author's Contributions}

Marco Fidaleo: Designed and performed the experiments and contributed to the analysis of results.

Roberto Lavecchia: Conceived the experiments, analyzed the data and wrote the paper.

Antonio Zuorro: Conceived the experiments, analyzed the data and wrote the paper.

\section{Ethics}

This article is original and contains unpublished material. The corresponding author confirms that all of the other authors have read and approved the manuscript and no ethical issues involved.

\section{References}

Andrade, B.F.M.T., L.N. Barbosa, I.D.S. Probst and A.F. Júnior, 2014. Antimicrobial activity of essential oils. J. Essential Oil Res., 26: 34-40. DOI: $10.1080 / 10412905.2013 .860409$

Basualdo, C., V. Sgroy, M.S. Finola and J.M. Marioli, 2007. Comparison of the antibacterial activity of honey from different provenance against bacteria usually isolated from skin wounds. Vet. Microbiol., 124: $375-381$.

DOI: $10.1016 /$ j.vetmic.2007.04.039

Cooper, R.A., P.C. Molan and K.G. Harding, 2002. The sensitivity to honey of gram-positive cocci of clinical significance isolated from wounds. J. Applied Microbiol., 93: 857-863. DOI: 10.1046/j.1365-2672.2002.01761.x

Escuredo, O., L.R. Silva, P. Valentão, M.C. Seij and P.B. Andrade, 2012. Assessing Rubus honey value: Pollen and phenolic compounds content and antibacterial capacity. Food Chem., 130: 671-678. DOI: 10.1016/j.foodchem.2011.07.107

Fidaleo, M., A. Zuorro and R. Lavecchia, 2010. Methylglyoxal: A new weapon against staphylococcal wound infections? Chem. Lett., 39: 322-323. DOI: $10.1246 / \mathrm{cl} .2010 .322$

Fidaleo, M., A. Zuorro and R. Lavecchia, 2011. Antimicrobial activity of some Italian honeys against pathogenic bacteria. Chem. Eng. Trans., 24: 1015-1020. DOI: 10.3303/CET1124170

Fidaleo, M., A. Zuorro and R. Lavecchia, 2013. Enhanced antibacterial and anti-quorum sensing activities of triclosan by complexation with modified $\beta$-cyclodextrins. World J. Microbiol. Biotechnol., 29: 1731-1736.

DOI: $10.1007 / \mathrm{s} 11274-013-1335-\mathrm{z}$
Hall, M.R., E. McGillicuddy and L.J. Kaplan, 2014. Biofilm: Basic principles, pathophysiology and implications for clinicians. Surgical Infect., 15: 1-7. DOI: $10.1089 /$ sur.2012.129

Hammond, E.N., E.S. Donkor and C.A. Brown, 2014. Biofilm formation of Clostridium difficile and susceptibility to Manuka Honey. BMC Complementary Alternative Med., 14: 329-329. DOI: $10.1186 / 1472-6882-14-329$

Jenkins, R. and R. Cooper, 2012. Improving antibiotic activity against wound pathogens with manuka honey in vitro. PLoS One, 7: e45600- e45600. DOI: 10.1371/journal.pone.0045600

Klancnik, A., S. Piskernik, B. Jersek and S.S. Mozina, 2010. Evaluation of diffusion and dilution methods to determine the antibacterial activity of plant extracts. J. Microbiol. Methods, 81: 121-126. DOI: 10.1016/j.mimet.2010.02.004

Kwakman, P.H.S. and S.A.J. Zaat, 2012. Antibacterial components of honey. IUBMB Life, 64: 48-55. DOI: $10.1002 /$ iub. 578

Kwakman, P.H.S., A.A. te Velde, L. de Boer, C.M.J.E. Vandenbroucke-Grauls and S.A.J. Zaat, 2011. Two major medicinal honeys have different mechanisms of bactericidal activity. PLoS One, 6: e17709- e17709. DOI: 10.1371/journal.pone.0017709

Lee, J.H., J.H. Park, J.A. Kim, G.P. Neupane and M.H. Cho et al., 2011. Low concentrations of honey reduce biofilm formation, quorum sensing and virulence in Escherichia coli O157: H7. Biofouling, 27: 1095-1104.

DOI: $10.1080 / 08927014.2011 .633704$

Livermore, D.M., 2011. Discovery research: The scientific challenge of finding new antibiotics. J. Antimicrobial Chemotherapy, 66: 1941-1944. DOI: $10.1093 / \mathrm{jac} / \mathrm{dkr} 262$

Lu, J., L. Turnbull, C.M. Burke, M. Liu and D.A. Carter et al., 2014. Manuka-type honeys can eradicate biofilms produced by Staphylococcus aureus strains with different biofilm-forming abilities. Peer J., 2: e326- e326. DOI: 10.7717/peerj.326

Maddocks, S.E. and R.E. Jenkins, 2013. Honey: A sweet solution to the growing problem of antimicrobial resistance? Future Microbiol., 8: 1419-1429. DOI: $10.2217 / \mathrm{fmb} .13 .105$

Majtan, J., J. Bohova, M. Horniackova, J. Klaudiny and V. Majtan, 2014. Anti-biofilm effects of honey against wound pathogens Proteus mirabilis and Enterobacter cloacae. Phytotherapy Res., 28: 69-75. DOI: $10.1002 /$ ptr.4957

Mandal, M.D. and S. Mandal, 2011. Honey: Its medicinal property and antibacterial activity. Asian Pacific J. Tropical Biomed., 1: 154-160. DOI: 10.1016/S2221-1691(11)60016-6 
Massaro, C.F., D. Shelley, T.A. Heard and P. Brooks, 2014. In vitro antibacterial phenolic extracts from "sugarbag" pot-honeys of Australian stingless bees (Tetragonula carbonaria). J. Agric. Food Chem., 62: 12209-12217. DOI: 10.1021/jf5051848

Mavric, E., S. Wittmann, G. Barth and T. Henle, 2008. Identification and quantification of methylglyoxal as the dominant antibacterial constituent of Manuka (Leptospermum scoparium) honeys from New Zealand. Mol. Nutr. Food Res., 52: 483-489. DOI: $10.1002 / \mathrm{mnfr} .200700282$

Nazzaro, F., F. Fratianni and R. Coppola, 2013. Quorum sensing and phytochemicals. Int. J. Mol. Sci., 14: 12607-12619. DOI: 10.3390/ijms 140612607

O'Gara, J.P. and H. Humphreys, 2001. Staphylococcus epidermidis biofilms: Importance and implications. J. Med. Microbiol., 50: 582-587. DOI: $10.1099 / 0022-1317-50-7-582$

Otto, M., 2009. Staphylococcus epidermidis-the 'accidental' pathogen. Nat. Rev. Microbiol., 7: 555-567. DOI: 10.1038/nrmicro2182

Pagès, J.M., C.J. James and M. Winterhalter, 2008. The porin and the permeating antibiotic: A selective diffusion barrier in Gram-negative bacteria. Nat. Rev. Microbiol., 6: 893-903. DOI: $10.1038 /$ nrmicro 1994

Purrello, S.M., R.S. Daum, G.F.S. Edwards, G. Lina and J. Lindsay et al., 2014. Meticillin-Resistant Staphylococcus Aureus (MRSA) update: New insights into bacterial adaptation and therapeutic targets. J. Global Antimicrobial Resistance, 2: 61-69. DOI: 10.1016/j.jgar.2014.02.003

Rossolini, G.M., F. Arena, P. Pecile and S. Pollini, 2014. Update on the antibiotic resistance crisis. Clin. Opin. Pharmacol., 18: 56-60. DOI: 10.1016/j.coph.2014.09.006

Savka, M.A., L. Dailey, M. Popova, R. Mihaylova and B. Merritt et al., 2015. Chemical composition and disruption of quorum sensing signaling in geographically diverse United States propolis. Evidence-Based Complementary and Alternative Med., 2015: 472593-472603.

DOI: $10.1155 / 2015 / 472593$
Silver, L.L., 2011. Challenges of antibacterial discovery. Clin. Microbiol. Rev., 24: 71-109.

DOI: 10.1128/CMR.00030-10

Truchado, P., A. Gil, F.A. Tomás-Barberán and A. Allende, 2009a. Inhibition by chestnut honey of Nacyl-l-homoserine lactones and biofilm formation in Erwinia carotovora, Yersinia enterocolitica and Aeromonas hydrophila. J. Agric. Food Chem., 57: 11186-11193. DOI: 10.1021/jf9029139

Truchado, P., F. Lopez-Galvevez, M.I. Gil, F.A. TomasBarberan and A. Allende, 2009b. Quorum sensing inhibitory and antimicrobial activities of honeys and the relationship with individual phenolics. Food Chem., 115: 1337-1344.

DOI: 10.1016/j.foodchem.2009.01.065

Truchado, P., F.A. Tomás-Barberán, M. Larrosa and A. Allende, 2012. Food phytochemicals act as quorum sensing inhibitors reducing production and/or degrading autoinducers of Yersinia enterocolitica and Erwinia carotovora. Food Control, 24: 78-85. DOI: 10.1016/j.foodcont.2011.09.006

Vandamme, L., A. Heyneman, H. Hoeksema, J. Verbelen and S. Monstrey, 2013. Honey in modern wound care: A systematic review. Burns, 39: 1514-1525. DOI: 10.1016/j.burns.2013.06.014

Wu, H., C. Moser, H.Z. Wang, N. Høiby and Z.J. Song, 2015. Strategies for combating bacterial biofilm infections. Int. J. Oral Sci., 7: 1-7.

DOI: $10.1038 /$ ijos.2014.65

Zainol, M.I., K.M. Yusoff and M.Y.M. Yusof, 2013. Antibacterial activity of selected Malaysian honey. BMC Complementary Alternative Med., 13: 129-129. DOI: 10.1186/1472-6882-13-129 